\title{
SCIDoC
}

International Journal of Dentistry and Oral Science (IJDOS)

ISSN: 2377-8075

\section{Awareness Of Food Sources Of Antioxidants Among Dental Students}

Research Article

Nikita Sivakumar ${ }^{1}$, Dhanraj Gnapathy² ${ }^{2}$, Kiran Kumar ${ }^{3}$

${ }^{1}$ Saveetha Dental College and Hospitals, Saveetha Institute of Medical and Technical Sciences, Saveetha University, Chennai-77, India.

${ }^{2}$ Professor and Head, Department of Prosthodontics, Saveetha Dental College and Hospitals, Saveetha Institute of Medical and Technical Sciences, Saveetha University, Chennai-77, India.

${ }^{3}$ Senior Lecturer, Department of Prosthodontics, Saveetha Dental College and Hospitals, Saveetha Institute of Medical and Technical Sciences, Saveetha University, Chennai-77, India.

\section{Abstract}

The aim of this study is to determine the understanding regarding awareness on food sources of antioxidants among dental students. The purpose of this study is to create awareness and determine the understanding of food sources of antioxidants among dental students. This study was conducted based on a questionnaire which consists of 10 questions through a weblinked application called Google Form. A convenient sample size of 100 consecutive dental students who are currently pursuing their studies in Chennai participated in the study. As an overall result, most of the participants are aware of food sources of antioxidants among dental students. As a conclusion, awareness on food sources of antioxidants among dental students in Chennai is adequate but certain knowledge has to be brushed up among them for a better understanding regarding this topic. Furthermore, they need to be trained on these grounds to help them be more disciplined and more consent with oral health issues.

Keywords: Antioxidants; Food Sources; Dental Students.

\section{Introduction}

In recent years there is an upsurge in the areas related to newer developments in prevention of disease especially the role of free radicals and antioxidants. This review compiles the pertinent possible role of 'free radicals' in disease and 'antioxidants' in its prevention, especially the current status of the antioxidants in oral diseases and future prospects and their application in dentistry. (Chu, 2012) Antioxidants are compounds used by aerobic organisms for protection against oxidative stress, induced by free radicals and active oxygen species. They exert their protective action either by suppressing the formation of free radicals or by scavenging free radicals (Papas, 2019). A wide range of biological effects, established experimentally, may inhibit carcinogenesis. These include effects on tumor initiation, promotion and progression, cell proliferation and differentiation, as well as DNA repair, cell membrane stability and immune function. (RigassioRadler, 2003)

Dietary antioxidants such as carotenoids, vitamins $\mathrm{C}$ and $\mathrm{E}$ and selenium have received much attention as potential cancer chemopreventive agents.(Devasagayamet al., 2004) Antioxidants, natural or synthetic food preservatives, are additives that preserve food from "farm to plate" and militate against oxidative deterioration on storage and processing. Due to their high stability and low volatility, the antioxidants help to maintain the level of nutrients, the texture, color, taste, freshness, functionality, aroma, and appeal to consumers such as the older person, ceteris paribus.(Hujoel and Lingström, 2017)

Antioxidants are not only in food additives but are also to be found in food supplements and levels should be measured, as such, in body tissues and fluids.(Touger-Decker, 2003) Lesser

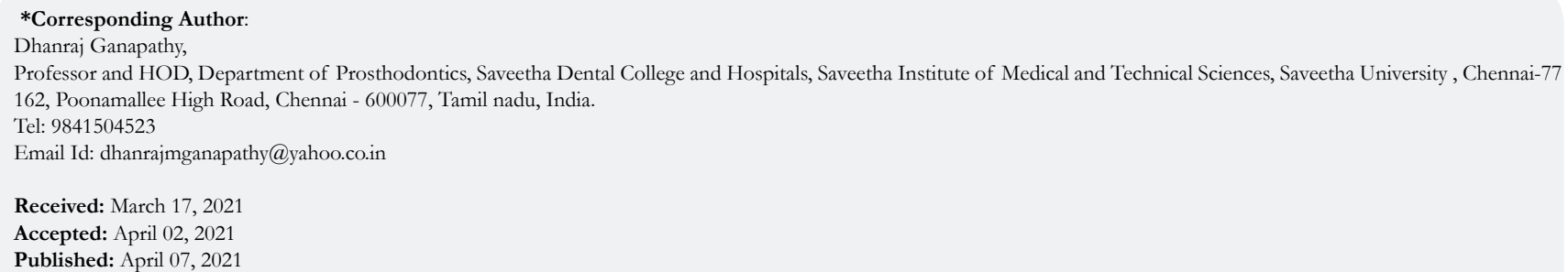

Citation: Nikita Sivakumar, Dhanraj Gnapathy, Kiran Kumar. Awareness Of Food Sources Of Antioxidants Among Dental Students. Int J Dentistry Oral Sci. 2021 ;08(04):2251-2255. doi: http://dx.doi.org/10.19070/2377-8075-21000445

Copyright: Dhanraj Ganapathy ${ }^{\circ} 221$. This is an open-access article distributed under the terms of the Creative Commons Attribution License, which permits unrestricted use, distribution and reproduction in any medium, provided the original author and source are credited. 
known sources of antioxidants to that cited in reference abound, for example, black chokeberry (Aroniamelanocarpa) found in juices, purees, jams, and so forth which, containing high levels of polyphenols and flavonoids, has potential interventive value for a range of chronic diseases such as diabetes and cardiovascular diseases.(Bloomer, 2007) Fermented grain food supplements also contain antioxidants, e.g., Antioxidant Biofactor, reducing lipid oxidation by scavenging upon the peroxyl radical.(Rao and Agarwal, 1998).

Antioxidants are essential for animal and plant life since they are involved in complex metabolic and signaling mechanisms.(Prasad et al., 1999) They protect plants by producing phytoalexins, e.g., isoflavonoid structures, in response to microbiological and fungal pathogen invasion. In terms of dietary intervention, mechanisms relating to, for example, microglia senescence(Singh and Gaby, 1991) and neural ageing should be sought which allow effective nutrient treatments to be developed in the form of e.g., functional foods and plant supplements that may develop our understanding of abnormal ageing and onset of neurodegenerative diseases. (Kaugarset al., 1994)

Excellent reviews on free radicals and related topics which impact on human health e.g., Lobo et al(Lobo et al., 2010), However the blind should not lead the blind because for many reasons due to study design, insufficient statistical power, the nature of cohorts, the follow-up timespan, response evaluation, etc., conflicting results may arise and affect health promotion programs e.g., resveratrol.(Carnelio, Khan and Rodrigues, 2007) An increasingly active area of research is the existing metabolome of the human gut either under the influence of a "usual" diet or one which may be transformed or manipulated by dietary antioxidant interventions,(Shetti, Keluskar and Aggarwal, 2009) e.g., flavonoids, carotenoids, etc. focusing on gut-brain interactions, vide infra. This overview focused on the health of older persons, of which neurodegenerative diseases are becoming more prevalent, Increasingly, as more structural information is gleaned from natural products possessing antioxidative,(Meyers, Maloley and Weeks, 1996) anti-inflammatory, anti-amyloidogenic properties, new synthetic structures can be developed to potentially become the next generation of product for these diseases, such as Alzheimer's disease.(Rao, Guns and Rao, 2003)

In simplest terms, food antioxidants are scavengers of free radicals, which is a chemical structure that has at least one unpaired electron which can cause cellular and genetic changes due to their highly reactive state that can act to produce damage over the $\mathrm{nm}$ range, e.g., the hydroxyl radical;(Kumar et al., 2007) other oxygen radicals include the hydroperoxyl, alkyloxy, and superoxide anion; an important nitrogen containing radical is nitric oxide; sulfur containing radicals include thiols and disulfide anions; and carbon containing radicals include the carbonate group.(Singh et al., 2004) A detailed review about the radicals and food antioxidants can be found in a paper from this group.(Van Poppel and Goldbohm, 1995)

As would be expected, of the four million radicals produced per day, a balance must be struck between potential cellular/tissue damage and the benefits of radicals needed for healthy intra- and inter-cellular signaling processes. Indeed, the oxidation of food as a source of body heat and locomotion was due to Lavoisier in 1775;(Willett, 1990) an analogy being fuel for a power-driven vehicle; and reported some years later. Therefore, this study is aimed to study the awareness of food sources of antioxidants among dental students in Chennai. This study is conducted using a survey based questionnaire analysis.

\section{Materials and Methods}

A convenience sample size of 122 consecutive general publics who are currently staying in Chennai participated in this study. A cross-sectional observational online based study was conducted. Questionnaire was constructed on the Google Form website with demographic details and dichotomous responses (True, False, I don't know). The questionnaire consists of 21 questions as shown in Table 1. A link containing these questionnaires was shared with all the participants and required them to answer the questions. All the responses were analysed and recorded.Table 1 shows the question asked in the questionnaire.

\section{Results}

According to figure 1, all the awareness questions asked in the questionnaire got a good response where many participants have claimed that they are aware of the food sources of antioxidants. Other questions' responses were also shown to a highly aware response regarding this topic among the participants (dental students). About $17.8 \%$ of the participants were first year dental students, $27.7 \%$ were second year students, $16.8 \%$ were third year dental students, final years were $16.8 \%$ and interns were $20.8 \%$. Overall an almost equal distribution of dental students from all

Table 1. Shows the question asked in the questionnaire.

\begin{tabular}{|l|}
\hline QUESTIONS \\
\hline Q1. Are you aware of the function of antioxidants in our body? \\
\hline Q2. Do you know the food source of antioxidants? \\
\hline Q3. The biofactor of antioxidants is reducing lipid oxidation by scavenging upon peroxyl radical? \\
\hline Q4. Red grapes and blueberries are rich in antioxidants? \\
\hline Q5. There are two type of types of antioxidants, that is enzymatic and \\
\hline Q6. Antioxidants are also known as free radicals scavengers? \\
\hline Q7. Pumpkin and mango are rich in beta carotene? \\
\hline Q8. Onions, garlics and leek helps in increasing the allium sulphur compounds which is another rich component of antioxidants? \\
\hline Q9. Cranberries and red wines are two most trustable sources of anti aging due to high levels of antioxidants? \\
\hline Q10. The antioxidants help in defending your cells from damage? \\
\hline
\end{tabular}


Figure 1. Shows the dichotomous responds to questions asked regarding knowledge of antioxidants.

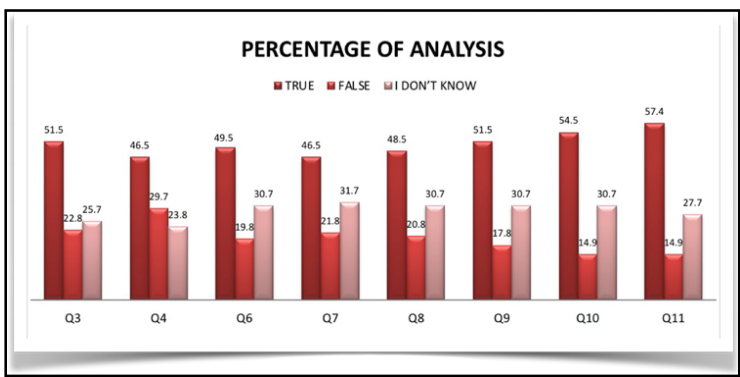

Figure 2. Shows the responds regarding questions asked about vitamins in the antioxidants.

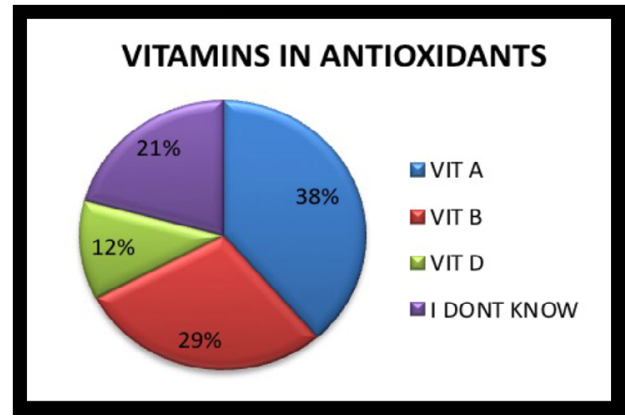

Figure 3. Shows the responds regarding questions asked about enzymes involved in antioxidants.

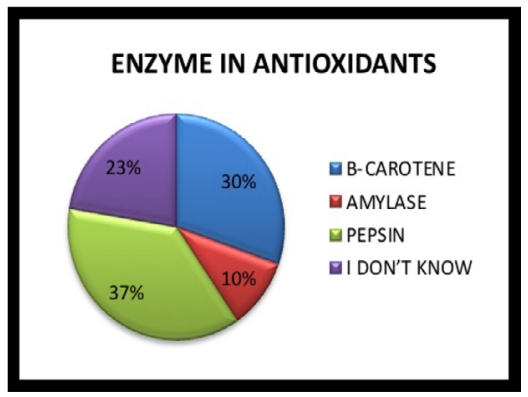

Figure 4. Shows the response for question asked regarding the source of antioxidants.

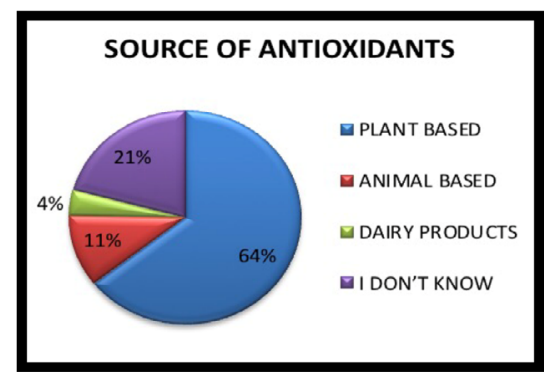

Figure 5. Shows the response for question asked about the awareness of the functions of the antioxidants.

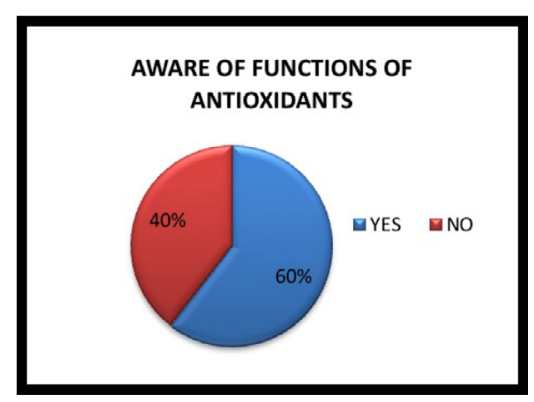

the years were seen. Moreover in gender distribution, it showed about $59.4 \%$ of them were female participants whereas the remaining $40.6 \%$ were male participants.

Figure 2 explained that $38 \%$ of the participants chose the option vitamin $\mathrm{A}$ as the answer for a question asked about the involved vitamins in the antioxidant. Remaining $29 \%, 21 \%, 12 \%$ of the participants chose the option vitamin B, I don't know, Vitamin D, respectively. Figure 3 showed the response from the participants regarding questions asked about the enzymes involved in antioxidants. About $30 \%$ of the participants answered B-carotene, $37 \%$ of them answered pepsin, $10 \%$ of them answered amylase and 
Figure 6. Shows the response towards a question asked about the awareness of the source of antioxidants.

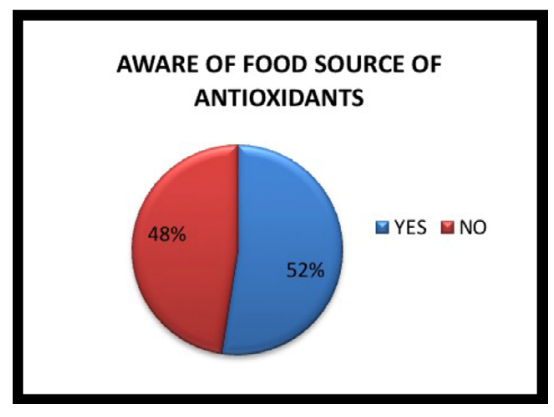

$23 \%$ of them had no clue about this question.

Majority $(64 \%)$ of the participants were aware about the source of antioxidants where they answered plant based, as shown in Figure 4 . Remaining $11 \%$ and $4 \%$ of the participants chose the option animal based and dairy products, respectively. However, $21 \%$ of the participants chose the I don't know option as they lacked the knowledge to answer this question. Figure 5 explained the awareness of the participants regarding functions of antioxidants, where $60 \%$ of them answered yes and $40 \%$ ofthe answered no. Figure 6 was also showing awareness of food sources of antioxidants. $52 \%$ of the participants were aware of the food source of antioxidants, whereas $48 \%$ of them were not aware regarding this.

\section{Discussion}

Various studies have shown the role of antioxidants in the caries prevention, and a study done by Shetty et al. has reported that free radicals in tobacco smoke increase the prevalence of dental caries. Another study done by Aronson et al.(Aronson, 2005) revealed that there is an association between Total Antioxidant Capacity of saliva and dental caries and this may be helpful in caries prevention. In the present study, the knowledge of antioxidants in dental students is fair. As $40.6 \%$ males and $59.4 \%$ of females responded neither true nor false, it can be attributed to lack of knowledge or due to limited studies that show the food sources of antioxidants among dental students. Moreover, when the dental students were asked where they got the maximum information regarding antioxidants, it was highlighted that their main source of information was from articles (48\%) followed by the internet (32\%). Whereas usage of books and newspapers for information was only $15 \%$ and $4 \%$ respectively.

Our results are in agreement to Patil et al.,(Patil, Kumar and $\mathrm{Mu}-$ noli, 2015) whose study reported that the majority of graduate $(40 \%)$ and postgraduate dentists $(31.3 \%)$ gained their knowledge through journal articles only. These statistics confirm our assumption that nowadays, most practitioners prefer to spend their time on their computers and pads, and prefer to read journals online on their devices, leading to increased computer and internet use. A study conducted by Singh et al.(Singh and Singh, 2019) concluded that computer knowledge was high among dental students but its dental application was limited compared with general purpose. However use of books and newspapers was low it may be due to their busy schedule or lack of interest. Although dental practitioners in our community displayed positive beliefs in the usefulness of antioxidants and their role in oral health care, further research is needed to extensively appraise their knowledge, practice and extent of awareness about other forms of antioxidants, for which dentists may play a crucial role in counseling society.

Hence to conclude that, dental health personnel have good knowledge and attitudes towards natural antioxidants, but execution of their knowledge in their profession is inadequate. All dental health personnel teaching in dental institutes in Tricity should consider natural antioxidants as part of the teaching course and heed to the task. Thus, to improve health care provisions, not only dentists, but other professionals should also be exposed to this course.(Nagelberg, 2014) So in order for this to be done, they should start exercising the use of antioxidants regularly in order to acquire, improve or maintain good oral as well as general health, since the results have shown that due to lack of knowledge the use of antioxidants is very finite. Furthermore natural antioxidants should be used in cancer patients to reduce treatment cost and to prevent the onset of cancer in normal people. Patients will tolerate standard treatment better, experience less weight loss, have a better quality of life, and most importantly, live longer than patients receiving no antioxidants. Thus, the burden of cancer and periodontal diseases in India will be reduced.

\section{Conclusion}

Within the limitations of the study, we have concluded that the majority of dental students have fair knowledge about lithium disilicate crowns. However, this study was limited to only one dental institute in Chennai and only 100 students participated. Furthermore, this study should be conducted in a larger scale area and sample size to get a proper overview regarding this topic within dental students concerning the new advent technologies.

\section{Acknowledgement}

We, the authors of the manuscript, would like to thank and acknowledge Saveetha Dental College for allowing us to distribute questionnaires to their students for our study.

\section{Author Contributions}

All authors have equal contribution in bringing out this research work.

\section{References}

[1]. Aronson JK. Side Effects of Drugs Annual: A Worldwide Yearly Survey of New Data and Trends in Adverse Drug Reactions. Elsevier Science.2005.

[2]. Bloomer RJ. Decreased blood antioxidant capacity and increased lipid peroxidation in young cigarette smokers compared to nonsmokers: Impact of dietary intake. Nutr J. 2007 Nov 8;6:39. PubmedPMID: 17996062.

[3]. Carnelio S, Khan SA, Rodrigues GS. Free radicals and antioxidant therapy 
in clinical practice: to be or not to be? J Coll Physicians Surg Pak. 2007 Mar;17(3):173-4. PubmedPMID: 17374307.

[4]. Chu PP. Embedded SoPC design with NIOS II processor and Verilog examples. John Wiley \& Sons; 2012 May 14.

[5]. Devasagayam TP, Tilak JC, Boloor KK, Sane KS, Ghaskadbi SS, Lele RD. Free radicals and antioxidants in human health: current status and future prospects. J Assoc Physicians India. 2004 Oct;52:794-804. PubmedPMID: 15909857.

[6]. Hujoel PP, Lingström P. Nutrition, dental caries and periodontal disease: a narrative review. J ClinPeriodontol. 2017 Mar;44Suppl 18:S79-S84. PubmedPMID: 28266117.

[7]. Kaugars GE, Silverman S Jr, Lovas JG, Brandt RB, Riley WT, Dao Q, et al. A clinical trial of antioxidant supplements in the treatment of oral leukoplakia. Oral Surg Oral Med Oral Pathol. 1994 Oct;78(4):462-8. PubmedPMID: 7800378 .

[8]. Kumar A, Bagewadi A, Keluskar V, Singh M. Efficacy of lycopene in the management of oral submucous fibrosis. Oral Surg Oral Med Oral Pathol Oral RadiolEndod. 2007 Feb;103(2):207-13. PubmedPMID: 17234537.

[9]. Lobo V, Patil A, Phatak A, Chandra N. Free radicals, antioxidants and functional foods: Impact on human health. Pharmacogn Rev. 2010 Jul;4(8):11826. PubmedPMID: 22228951.

[10]. Meyers DG, Maloley PA, Weeks D. Safety of antioxidant vitamins. Arch Intern Med. 1996 May 13;156(9):925-35. PubmedPMID: 8624173.

[11]. NagelbergRH. 'Antioxidant therapy', Dental economics - oral hygiene.2014; 104(2):4.

[12]. PapasAM. Antioxidant Status of the Digesta and Colon Cancer: Is There a Direct Link?',Antioxidant Status, Diet, Nutrition, and Health.2019;431-447. doi: 10.1201/9780367811099-19.

[13]. Patil K, Kumar V, Munoli K. Knowledge and attitude of dental surgeons in India toward ocular complications of intra-oral local anesthesia. J Nat SciBiol Med. 2015 Jul-Dec;6(2):286-90. PubmedPMID: 26283814.

[14]. Prasad KN, Kumar A, Kochupillai V, Cole WC. High doses of multiple antioxidant vitamins: essential ingredients in improving the efficacy of stand- ard cancer therapy. J Am CollNutr. 1999 Feb;18(1):13-25. PubmedPMID: 10067654.

[15]. Rao AV, Agarwal S. Bioavailability and in vivo antioxidant properties of lycopene from tomato products and their possible role in the prevention of cancer. Nutr Cancer. 1998;31(3):199-203. PubmedPMID: 9795972.

[16]. Rao LG, Guns E, Rao AV. Lycopene: Its role in human health and disease. Agro Food. 2003 Jul 1;7:25-30.

[17]. RigassioRadler D. Nutritional supplements, ergogenic aids, and herbals. Dent Clin North Am. 2003 Apr;47(2):245-58, vi. PubmedPMID: 12699230.

[18]. Shetti A, Keluskar V, Aggarwal A. Antioxidants: Enhancing oral and general health. Journal of Indian Academy of Oral Medicine and Radiology. 2009 Jan $1 ; 21(1): 1$

[19]. Singh M, Krishanappa R, Bagewadi A, Keluskar V. Efficacy of oral lycopene in the treatment of oral leukoplakia. Oral Oncol. 2004 Jul;40(6):591-6. PubmedPMID: 15063387.

[20]. Singh M, Singh S, editors. Survismeter: Fundamentals, Devices, and Applications. CRC Press; 2019 Jan 30.

[21]. Singh VN, Gaby SK. Premalignant lesions: role of antioxidant vitamins and beta-carotene in risk reduction and prevention of malignant transformation. Am J ClinNutr. 1991 Jan;53(1 Suppl):386S-390S. PubmedPMID: 1985417.

[22]. Touger-Decker R. Clinical and laboratory assessment of nutrition status in dental practice. Dent Clin North Am. 2003 Apr;47(2):259-78. PubmedPMID: 12699231.

[23]. vanPoppel G, Goldbohm RA. Epidemiologic evidence for beta-carotene and cancer prevention. Am J ClinNutr. 1995 Dec;62(6 Suppl):1393S-1402S. PubmedPMID: 7495237.

[24]. Willett WC. Vitamin A and lung cancer. Nutr Rev. 1990 May;48(5):201-11. PubmedPMID: 2196482. 